(C) The Author(s), 2020. Published by Cambridge University Press on behalf of The Nutrition Society. This is an Open Access article, distributed under the terms of the Creative Commons Attribution licence (http://creativecommons.org/licenses/by/4.0/), which permits unrestricted re-use, distribution, and reproduction in any medium, provided the original work is properly cited.

\title{
Plasma mineral (selenium, zinc or copper) concentrations in the general pregnant population, adjusted for supplement intake, in relation to thyroid function
}

\author{
Victor Pop ${ }^{1 *}$, Johannes Krabbe ${ }^{2}$, Wolfgang Maret ${ }^{3}$ and Margaret Rayman ${ }^{4}$ \\ ${ }^{1}$ Department of Medical and Clinical Psychology, Tilburg University, 500 LE Tilburg, The Netherlands \\ ${ }^{2}$ Department of Clinical Chemistry and Laboratory Medicine, Medisch Spectrum Twente, Medlon BV, Enschede, The Netherlands \\ ${ }^{3}$ Department of Nutritional Sciences, School of Life Course Sciences, Faculty of Life Sciences and Medicine, King's College \\ London, London SE1 9NH, UK \\ ${ }^{4}$ Department of Nutritional Sciences, Faculty of Health and Medical Sciences, University of Surrey, Guildford GU2 7XH, UK \\ (Submitted 14 April 2020 - Final revision received 14 June 2020 - Accepted 7 July 2020 - First published online 14 July 2020)
}

\section{Abstract}

The present study reports on first-trimester reference ranges of plasma mineral Se/Zn/Cu concentration in relation to free thyroxine (FT4), thyrotropin (TSH) and thyroid peroxidase antibodies (TPO-Ab), assessed at 12 weeks' gestation in 2041 pregnant women, including 544 women not taking supplements containing Se/Zn/Cu. The reference range (2.5th-97.5th percentiles) in these 544 women was $0.72-1.25 \mu \mathrm{mol} / 1 \mathrm{for} S \mathrm{Se}$, $17.15-35.98 \mu \mathrm{mol} / \mathrm{l}$ for $\mathrm{Cu}$ and $9.57-16.41 \mu \mathrm{mol} / \mathrm{l}$ for $\mathrm{Zn}$. These women had significantly lower mean plasma Se concentration (0.94 (sD 0.12) $\mu \mathrm{mol} / \mathrm{l})$ than those $(n$ 1479) taking $\mathrm{Se} / \mathrm{Zn} / \mathrm{Cu}$ supplements (1.03 (sD 0.14$) \mu \mathrm{mol} / \mathrm{l} ; P<0.001$ ), while the mean $\mathrm{Cu}$ $(26.25 \mu \mathrm{mol} / \mathrm{l})$ and $\mathrm{Zn}(12.55 \mu \mathrm{mol} / \mathrm{l})$ concentrations were almost identical in these sub-groups. Women with hypothyroxinaemia (FT4 below reference range with normal TSH) had significantly lower plasma $\mathrm{Zn}$ concentrations than euthyroid women. After adjusting for covariates including supplement intake, plasma Se (negatively), Zn and $\mathrm{Cu}$ (positively) concentrations were significantly related to logFT4; Se and Cu (but not Zn) were positively and significantly related to logTSH. Women taking additional Se/Zn/Cu supplements were 1.46 (95\% CI 1.09, 2.04) times less likely to have elevated titres of TPO-Ab at 12 weeks of gestation. We conclude that first-trimester Se reference ranges are influenced by Se-supplement intake, while $\mathrm{Cu}$ and $\mathrm{Zn}$ ranges are not. Plasma mineral Se/Zn/Cu concentrations are associated with thyroid FT4 and TSH concentrations. $\mathrm{Se} / \mathrm{Zn} / \mathrm{Cu}$ supplement intake affects TPO-Ab status. Future research should focus on the impact of trace mineral status during gestation on thyroid function.

Key words: Selenium: Copper: Zinc: Pregnancy: Thyroid function

Adequate maternal thyroid function during pregnancy is crucial for optimal fetal development, especially during the first 20 weeks when the fetal thyroid does not produce its own thyroid hormones $(\mathrm{TH})^{(1)}$. Proper thyroid function is highly relevant because the development of the fetal central nervous system is dependent on $\mathrm{TH}^{(1)}$. Nutritional (trace) elements such as Se, $\mathrm{Zn}$ and $\mathrm{Cu}$ are involved in a diversity of mechanisms including: (i) the regulation of cellular function, (ii) growth and maintenance, and (iii) neuromodulation ${ }^{(2)}$. A deficiency of trace elements may result in alterations in immune function, cognition and growth and development ${ }^{(3,4)}$

For adult females, normal plasma Se concentrations vary according to location. In Europe, they are around $1.1 \mu \mathrm{mol} / \mathrm{l}$, whereas in the USA, they are more often $1.6 \mu \mathrm{mol} / \mathrm{l}^{(5)}$. Except perhaps for regions with high plasma Se concentration, plasma
Se may fall in pregnancy owing to plasma volume expansion ${ }^{(5)}$. $\mathrm{Zn}$ is important for many physiological functions such as growth, immune function and reproduction ${ }^{(6)}$. As part of the adaptive immune system, T cells are particularly sensitive to deficiency of $\mathrm{Zn}$ that is needed for their maturation and the maintenance of a balance between different T-cell subsets ${ }^{(4)}$. Cu has a crucial role in mitochondrial respiration, erythropoiesis, myelin formation, hormone synthesis, antioxidant protection and immune function ${ }^{(7)} . \mathrm{Cu}$ is important for the functioning of other dietary elements including $\mathrm{Fe}$. While Se and $\mathrm{Cu}$ have a role only in 2-3 dozen proteins, $\mathrm{Zn}$ is a constituent of about every tenth protein, that is, over 3000 human proteins are believed to be $\mathrm{Zn}$ proteins ${ }^{(8)}$. For the trace elements $\mathrm{Zn}$ and $\mathrm{Cu}$, the plasma reference ranges for adult females are 10-18 and 10-24 $\mu \mathrm{mol} / \mathrm{l}$, respectively ${ }^{(6,8)}$. In a study from China, reference ranges for $\mathrm{Cu}$

Abbreviations: FT4, free thyroxine; hCG, human chorionic gonadotropin; NHANES, National Health and Nutrition Examination Survey; TH, thyroid hormone; TPO-Ab, thyroid peroxidase antibodies; TSH, thyrotropin.

* Corresponding author: Victor Pop, email v.j.m.pop@uvt.nl 
and $\mathrm{Zn}$ were established in different groups of women at a number of gestational ages and were compared with those of 552 non-pregnant matched controls ${ }^{(9)}$. It was unclear whether the figures referred to plasma or serum concentrations and supplement intake was not recorded. The reference range for $\mathrm{Cu}$ was significantly lower for non-pregnant women (aged 21-38 years), at 7.9-24.9 $\mu \mathrm{mol} / \mathrm{l}$, than for any assessment during gestation. The non-pregnant reference range of $\mathrm{Zn}$ was $9 \cdot 7-16.9 \mu \mathrm{mol} / \mathrm{l}$ which only slightly differed from that in pregnancy ${ }^{(9)}$. In a recent Norwegian study of 2982 pregnant women, the median plasma $\mathrm{Se} / \mathrm{Zn} / \mathrm{Cu}$ concentrations assessed at 18 weeks' gestation were $1.29,7.35$ and $24.2 \mu \mathrm{mol} / 1$, respectively ${ }^{(10)}$. However, as the authors reported themselves, this was a highly selected subgroup of the original cohort of 112789 pregnant women accrued over a period of 10 years (1999-2008) making a bias likely ${ }^{(10)}$. A major limitation in determining standard reference ranges of trace elements during pregnancy is the widespread use of supplement intake during that life stage. In several Western countries, up to $70 \%$ of women take pregnancy supplements (folic acid, vitamin D, specific trace elements) ${ }^{(11)}$. Thus, a large sample size is needed in order to find subgroups of women not taking supplements containing these trace elements. These sub-groups should preferentially share similar characteristics with the main group, enabling researchers to adapt the reference ranges to the general pregnant population.

Se, as selenocysteine, is at the active centre of the selenoproteins $^{(5)}$. The iodothyronine deiodinases DIO1 and DIO2 are selenoproteins that convert thyroxine (T4) to the active hormone, triiodothyronine (T3); the deiodinases DIO1 and $\mathrm{DIO} 3$ are also able to convert $\mathrm{T} 4$ to inactive, reverse $\mathrm{T} 3^{(5)}$. A further important role for the glutathione peroxidase selenoprotein (GPX3) is the removal of excess hydrogen peroxide that, together with thyroid peroxidase, is needed for TH synthesis ${ }^{(5)}$. Low Se status has been associated with newly diagnosed Graves' disease and Hashimoto's thyroiditis ${ }^{(12,13)}$. $\mathrm{Zn}$ is also involved in thyroid hormone metabolism including regulation of deiodinase activity, thyroid releasing hormone and TSH (thyrotrophin) synthesis $^{(14)}$. Low plasma Zn concentration has been associated with hypothyroidism and high concentration with hyperthyroidism ${ }^{(13)}$. Especially relevant in pregnancy is the effect of Zn deficiency on the offspring's neuro-psychological functioning, activity and motor development ${ }^{(15)}$. Previously, a correlation between serum Se, $\mathrm{Zn}$ and $\mathrm{Cu}$ concentrations and thyroid function was reported in the general US population ${ }^{(16)}$. In females, Cu was significantly associated with log-transformed total thyroxine (logTT4), while Se was associated with logFT3 at the $90 \%$ significance level. No data were reported for pregnant women; women with elevated thyroid peroxidase antibodies (TPO-Ab) were excluded from the analyses ${ }^{(16)}$. Because pregnancy is characterised by fundamental changes in immune function and increasing demands for maternal $\mathrm{TH}$ to ensure proper fetal development, it is important to evaluate the possible role of these trace elements on gestational thyroid function.

Up to $8-15 \%$ of women of fertile age have elevated titres of $\mathrm{TPO}-\mathrm{Ab}+{ }^{(1)}$. TPO-Ab+ titres during early gestation definitely imply elevated titres before conception and are one of the most obvious signs of a thyroid that is compromised by an autoimmune process; these women are at high risk for having unidentified (sub)clinical thyroid dysfunction or developing thyroid dysfunction ${ }^{(1)}$. The relationship between plasma mineral (Se, $\mathrm{Zn}$ and $\mathrm{Cu}$ ) concentrations during pregnancy and TPO-Ab status has scarcely been addressed.

The primary aim of the present study was to evaluate firsttrimester standard reference ranges of plasma mineral (Se, Zn and $\mathrm{Cu}$ ) concentrations in a large cohort of healthy pregnant women, adjusting for supplement intake. The secondary aim was to investigate possible cross-sectional relationships between plasma mineral (Se, $\mathrm{Zn}$ and $\mathrm{Cu}$ ) concentrations in subgroups of women with different forms of thyroid dysfunction and TPO-Ab status. A tertiary aim was to compare plasma mineral (Se, Zn and $\mathrm{Cu}$ ) concentrations with $\mathrm{TH}$ concentrations during early gestation, adjusted for important determinants such as smoking, parity, BMI and family history of thyroid dysfunction. Fourth, we aimed to investigate the possible relationship between plasma mineral (Se, $\mathrm{Zn}$ and $\mathrm{Cu}$ ) concentrations and TPO-Ab status.

\section{Materials and methods}

The present report is part of the longitudinal prospective HAPPY project (Holistic Approach to Pregnancy and the first Postpartum Year), the details of which have been described elsewhere ${ }^{(17,18)}$.

\section{Participants and procedure}

From January 2013 to September 2014, pregnant women who had their first antenatal visit at one of the seventeen participating community midwife offices in the South-East of the Netherlands were invited to participate in the HAPPY project. During the 18 months of the recruitment period, approximately 4150 women visited the participating midwife offices. Only Dutch speaking women ( $n$ 3475) were invited to participate. Women ( $n$ 3159) were eligible of whom 2275 provided written informed consent $(\text { response rate }=72 \%)^{(16)}$. Of these, all obstetric and biological data were available in 2041 women. The study was approved by the Psychology Ethics Committee of Tilburg University (protocol number EC-2012.25) and additionally evaluated by the Medical Ethical Committee of the Máxima Medical Center in Veldhoven.

\section{Assessments}

This study is reported according to the STROBE guidelines ${ }^{(19)}$. At 12 weeks of gestation, as part of the standardised nationwide early-pregnancy blood assessment, non-fasting blood samples were collected in BD Vacutainer PST-tubes and women completed a set of questionnaires that asked about demographic and obstetric features and lifestyle habits.

\section{Thyroid function assessment}

At the 12th week of gestation, TSH, free thyroxine (FT4) and TPO-Ab concentrations were determined in heparinised plasma using electrochemiluminescence assays (Cobas_e 601; Roche Diagnostics). The non-pregnant reference range of TSH is $0 \cdot 40-4 \cdot 0 \mathrm{mU} / 1$, of FT4 $10 \cdot 0-24 \cdot 0 \mathrm{pmol} / \mathrm{l}$ and of TPO-Abs $<35 \mathrm{IU} / 1$. According to the American Thyroid Association guidelines, the reference ranges of TSH and FT4 during pregnancy 
were defined in TPO-Ab-negative women at the 12th gestational week using the 2.5 th and 97.5 th percentiles to define the lower and upper limits of normal thyroid function ${ }^{(20)}$. The following sub-groups of thyroid function were defined: (i) euthyroid (TSH and FT4 within the reference limit); (ii) overt thyroid dysfunction (TSH and FT4 outside the reference limits); (iii) sub-clinical thyroid dysfunction (TSH outside the reference limit with normal FT4); (iv) hypothyroxinaemia (FT4 $<2 \cdot 5$ th or $<5$ th percentile with normal TSH) and finally, (v) hyperthyroxinaemia (FT4 $>95$ th, or $>97.5$ th percentile with normal TSH concentration) $)^{(20)}$.

\section{Selenium, zinc and copper}

Plasma Se, Zn and Cu concentrations were measured at the 12th gestational week in heparinised plasma samples by inductively coupled plasma MS using a Nexion 300X instrument (PerkinElmer) in the kinetic energy discrimination mode. Samples were diluted 30 times in $0.5 \% \mathrm{HNO}_{3}$ and $0.01 \%$ triton in MiliQ AquaDest. $\mathrm{Se}, \mathrm{Cu}$ and $\mathrm{Zn}$ were measured employing helium at a flow rate of $1.0 \mathrm{ml} / \mathrm{min}$ as the kinetic energy discrimination gas to remove polyatomic interferences. Within- and betweenrun variation were assessed by CLSI guideline EP5-A2 and found to be $<3 \%$ for low and high concentrations of $\mathrm{Zn}$ and $\mathrm{Cu}$ in plasma and $<5 \%$ for Se. According to CLSI guideline EP 17-A2, the lower limit of quantitation was calculated at $0 \cdot 15$, 0.30 and $0.27 \mu \mathrm{mol} / \mathrm{l}$ for Se, $\mathrm{Zn}$ and $\mathrm{Cu}$, respectively. Certified reference materials Seronorm L1 or L2 (Nycomed) were used to monitor accuracy. During measurement of the samples of this study, for L1 (lot 1309438), values for Se, $\mathrm{Zn}$ and Cu were $0.99 \mu \mathrm{mol} / \mathrm{l}$ (reported analytical value $1.10 \mu \mathrm{mol} / \mathrm{l}$ with a range $0.96-1.25 \mu \mathrm{mol} / \mathrm{l})$, $17.4 \mu \mathrm{mol} / 1$ (reported analytical value $16.8 \mu \mathrm{mol} / \mathrm{l}$ and range $14.6-19.0 \mu \mathrm{mol} / \mathrm{l}$ ) and $17.9 \mu \mathrm{mol} / \mathrm{l}$ (reported analytical value $17 \cdot 1 \mu \mathrm{mol} / \mathrm{l}$ and range $15 \cdot 7-18 \cdot 5 \mu \mathrm{mol} / \mathrm{l}$ ), respectively. For L2 (lot 1309416), values for Se, $\mathrm{Zn}$ and $\mathrm{Cu}$ were $1.58 \mu \mathrm{mol} / \mathrm{l}$ (reported certified mean 1.75 and $1.52-1.98 \mu \mathrm{mol} / \mathrm{l}$ ), $25.7 \mu \mathrm{mol} / \mathrm{l}$ (reported certified mean $24.7 \mu \mathrm{mol} / \mathrm{l}$ range $21.5-28.0 \mu \mathrm{mol} / \mathrm{l})$ and $29.4 \mu \mathrm{mol} / \mathrm{l}$ (reported certified mean $29.1 \mu \mathrm{mol} / \mathrm{l}$ and range $26 \cdot 7-31.5 \mu \mathrm{mol} / \mathrm{l})$, respectively. Moreover, pooled sera were measured as well in order to monitor within-run variation at low and high concentrations.

\section{Supplement intake}

At 12 weeks' gestation, supplement intake was carefully investigated. Women were asked whether they used any supplement on a daily basis. In the Netherlands, most supplement tablets including $\mathrm{Se} / \mathrm{Zn} / \mathrm{Cu}$ belong to 2-3 widely used products in which the daily dose is carefully reported (as requested by law). These different tablets were all recorded, including the dose of the trace elements.

\section{Statistics}

The most recent guidelines of the Clinical Laboratory Standard Institute (vol. 28 no. 30, 2012) for defining reference ranges in the clinical laboratory advise that an adequate sample size for reliable numbers should at least contain 120 samples $^{(21)}$. The current sample size of 2041 amply meets this criterion.
Statistical analysis was performed using the IBM SPSS Statistics for Windows version 25.0 (IBM Corp.). The skewness and kurtosis of Se data were 0.62 and 1.59 , those of $\mathrm{Zn} 0.51$ and 0.71 and those of $\mathrm{Cu} 0.35$ and 0.31 , respectively; therefore, parametric testing was used to compare means between subgroups. Descriptive statistics ( $t$ test: $T(\mathrm{df})=$ value, $P)$, $\chi^{2}\left(\chi^{2}(\mathrm{df})=\right.$ value, $P$ and ANOVA: $F(\mathrm{df})=$ value, $\left.P\right)$ were used to analyse the prevalence of abnormal thyroid dysfunction in relation to plasma mineral ( $\mathrm{Se}, \mathrm{Zn}$ and $\mathrm{Cu}$ ) concentrations. We then compared plasma mineral (Se, $\mathrm{Zn}$ and $\mathrm{Cu}$ ) concentrations with log-transformed FT4 and TSH values adjusted for confounders, using linear regression. Finally, within the TPO$\mathrm{Ab}+$ group, we compared plasma mineral ( $\mathrm{Se}, \mathrm{Zn}$ and $\mathrm{Cu}$ ) concentrations and the relationship between Se/Zn/Cu supplement intake and TPO-Ab status, using logistic regression analysis.

\section{Results}

Table 1 shows the characteristics of 2041 women with thyroid parameters at 12 weeks' gestation.

Almost all women were Caucasian, the majority had a partner and two-thirds were highly educated. Up to $9 \%$ had an elevated titre of TPO-Ab (>35 IU/1) and $10 \%$ reported a history of thyroid dysfunction in the parents. In the entire group, $25 \%$ reported a previous miscarriage; this was $18.6 \%$ in the 1014 primiparous women and $32.7 \%$ in the 1027 multiparous women $\left(\chi^{2}(1)=52\right.$, $P<0 \cdot 001)$

In clinical chemistry, the commonly used cut-offs to determine reference ranges are the $2 \cdot 5$ th-97.5th percentiles, which in this cohort of 2041 women, for the plasma mineral (Se, Zn and $\mathrm{Cu}$ ) were: $0.75-1.31,17.59-36.37$ and 9.42-16.44 $\mu \mathrm{mol} / \mathrm{l}$, respectively. However, in the group of 544 women not taking $\mathrm{Se} / \mathrm{Zn} / \mathrm{Cu}$ supplements, these reference ranges were: $0 \cdot 72-1 \cdot 25$, 9.57-16.41 and 17.15-35.98 $\mu \mathrm{mol} / \mathrm{l}$, respectively. In many population-based studies of trace minerals, the 5th-95th percentiles are reported. In the present study of the total sample of 2041 women, for plasma mineral (Se, $\mathrm{Zn}$ and $\mathrm{Cu}$ ), the 5th-95th percentiles were $0 \cdot 79-1 \cdot 25,9 \cdot 97-15 \cdot 6$ and $18 \cdot 8-34 \cdot 3 \mu \mathrm{mol} / 1$, respectively, and in those not taking these supplements, they were: $0 \cdot 76-1 \cdot 17, \quad 10 \cdot 0-15 \cdot 4$ and $18 \cdot 4-34 \cdot 2 \mu \mathrm{mol} / 1$, respectively. In Table 2, different subgroups are shown with the corresponding plasma mineral (Se, $\mathrm{Zn}$ and $\mathrm{Cu}$ ) concentrations according to supplement intake.

The women not taking supplements containing Se (groups 1, 3, 4) showed significantly lower mean plasma Se concentrations than those who did (group 2): ANOVA (2037) $F=34 \cdot 7, P<0 \cdot 001$, while the mean plasma $\mathrm{Cu}$ and $\mathrm{Zn}$ concentrations were almost identical in these sub-groups. Based on these figures, we defined two groups: those taking supplements with Se/Zn/Cu (group 2, $n$ 1479, $73 \cdot 3 \%$ ) and those who did not (groups $1+3+4: n 544,26 \cdot 7 \%$ ). Women not taking Se/Zn/Cu supplements had significantly lower mean Se concentration (0.96 (sD 0.14) $\mu \mathrm{mol} / \mathrm{l}$ ) than those with supplement intake (1.03 (sD 0.14) $\mu \mathrm{mol} / \mathrm{l}), T$ (2039): 9.9, $P<0.001$ ), while mean concentrations of $\mathrm{Zn}(12.55 v 12.57 \mu \mathrm{mol} / \mathrm{l})$ and $\mathrm{Cu}(26.25 v$ $26.29 \mu \mathrm{mol} / \mathrm{l})$ were almost identical in both groups. There were no significant differences in demographics, parity, educational 
Table 1. Characteristics of 2041 women with thyroid-hormone parameters assessed at 12 weeks' gestation (Numbers and percentages; mean values and standard deviations; median values and ranges)

\begin{tabular}{|c|c|c|c|c|c|c|}
\hline & Mean & SD & $n$ & $\%$ & Median & Range \\
\hline \multicolumn{7}{|l|}{ Demographic features } \\
\hline Caucasian & & & 2021 & 99 & & \\
\hline Age (years) & 30.5 & 3.5 & & & $21-40$ & \\
\hline \multicolumn{7}{|l|}{ Educational level } \\
\hline Low & & & 578 & $28 \cdot 3$ & & \\
\hline Medium & & & 114 & $5 \cdot 6$ & & \\
\hline High & & & 1349 & $66 \cdot 1$ & & \\
\hline \multicolumn{7}{|l|}{ Marital status } \\
\hline With partner & & & 1931 & $94 \cdot 6$ & & \\
\hline Single & & & 110 & $5 \cdot 4$ & & \\
\hline \multicolumn{7}{|l|}{ Obstetric features } \\
\hline Primiparous & & & 1002 & $49 \cdot 1$ & & \\
\hline Previous miscarriage & & & 508 & $24 \cdot 9$ & & \\
\hline \multicolumn{7}{|l|}{ Lifestyle habits during pregnancy } \\
\hline Smoking & & & 126 & $6 \cdot 2$ & & \\
\hline Any alcohol intake & & & 73 & 3.6 & & \\
\hline Pre-pregnancy BMI $\left(\mathrm{kg} / \mathrm{m}^{2}\right)$ & $23 \cdot 8$ & $3 \cdot 7$ & & & & \\
\hline BMI between 25 and $30 \mathrm{~kg} / \mathrm{m}^{2}$ & & & 469 & 23 & & \\
\hline BMI between 30 and $35 \mathrm{~kg} / \mathrm{m}^{2}$ & & & 142 & 7 & & \\
\hline $\mathrm{BMI}>35 \mathrm{~kg} / \mathrm{m}^{2}$ & & & 41 & 2 & & \\
\hline \multicolumn{7}{|l|}{ Thyroid parameters } \\
\hline TSH $(\mathrm{mlU} / \mathrm{l})$ & 1.76 & 2.93 & & & 1.47 & $0.01-27 \cdot 6$ \\
\hline $\log \mathrm{TSH}(\mathrm{mlU} / \mathrm{l})$ & 0.14 & 0.34 & & & 0.16 & -2.0 to 1.44 \\
\hline FT4 (pmol/l) & 14.5 & 2.48 & & & 14.34 & $4.6-32.8$ \\
\hline $\log$ FT4 (pmol/l) & $1 \cdot 16$ & 0.05 & & & $1 \cdot 16$ & $0.66-1.52$ \\
\hline TPO-Ab $>35$ IU/l & & & 179 & 8.6 & & \\
\hline History of thyroid dysfunction in parents & & & 204 & 10 & & \\
\hline
\end{tabular}

Low, primary education or secondary pre-vocational education; medium, secondary education or vocational education; high, Bachelor or Master's degree; TSH, thyrotropin; FT4, free thyroxine; TPO-Ab, thyroid peroxidase antibodies.

Table 2. Plasma concentration of selenium, zinc and copper ( $\mu \mathrm{mol} / \mathrm{l})$ in healthy pregnant women, categorised by supplement use during early gestation* (Numbers and percentages; mean values and standard deviations; median values and ranges)

\begin{tabular}{|c|c|c|c|c|c|c|c|c|c|c|c|}
\hline & \multicolumn{2}{|c|}{ Total sample } & \multicolumn{3}{|c|}{ Se } & \multicolumn{3}{|c|}{$\mathrm{Zn}$} & \multicolumn{3}{|c|}{$\mathrm{Cu}$} \\
\hline & $n$ & $\%$ & Mean & SD & Median & Mean & SD & Median & Mean & SD & Median \\
\hline 1. No supplement use & 252 & $12 \cdot 3$ & 0.94 & $0 \cdot 12$ & 0.94 & 12.42 & 1.59 & $12 \cdot 43$ & $26 \cdot 50$ & 4.95 & $26 \cdot 05$ \\
\hline 2. Daily supplements with $\mathrm{Se}, \mathrm{Zn}$ and $\mathrm{Cu}$ & 1497 & $73 \cdot 3$ & 1.03 & $0 \cdot 14$ & 1.02 & $12 \cdot 56$ & $1 \cdot 82$ & 12.46 & $26 \cdot 25$ & $4 \cdot 75$ & $25 \cdot 87$ \\
\hline 3. Folic acid (alone or + vitamin D) & 240 & 11.8 & 0.96 & 0.13 & 0.95 & $12 \cdot 60$ & 1.82 & $12 \cdot 32$ & $26 \cdot 20$ & 4.42 & $25 \cdot 79$ \\
\hline 4. Vitamin D alone & 52 & 2.5 & 0.95 & 0.20 & 0.94 & $12 \cdot 90$ & $2 \cdot 26$ & $12 \cdot 40$ & $25 \cdot 71$ & $4 \cdot 79$ & $26 \cdot 26$ \\
\hline
\end{tabular}

* On daily base intake of Se: $27 \cdot 5-55 \mu \mathrm{g}$; of $\mathrm{Zn}: 5-10 \mathrm{mg}$ and of $\mathrm{Cu}: 1 \mathrm{mg}$

level, smoking habits, alcohol intake, age and BMI between these two groups.

Based on the guidelines of the American Thyroid Association $^{(20)}$, the different sub-groups of women with thyroid dysfunction are shown with their TPO-Ab status and corresponding mean and standard deviation $\mathrm{Se} / \mathrm{Zn} / \mathrm{Cu}$ values for those subgroups, regardless of TPO-Ab status (Table 3 ).

With regard to plasma Se concentration, using the euthyroid group as the reference group, there was no significant difference between the different sub-groups and the reference group ( $t$ test). With regard to plasma $Z n$ concentration, the lowest mean concentration, that is, 11.97 (SD 1.58) $\mu \mathrm{mol} / \mathrm{l}$, was found in hypothyroxinaemic women, which was significantly different from that of the euthyroid group $(T(1885)=2 \cdot 3, P=0 \cdot 019)$. In the present study, the highest plasma $\mathrm{Zn}$ concentrations were found in women with clinical (overt) thyroid dysfunction (hypothyroidism $n$ 11, and hyperthyroidism $n$ 17). Taking these women together ( $n$ 28), women with overt thyroid dysfunction had significantly higher plasma $\mathrm{Zn}$ concentrations than the euthyroid group $(T(1861)=2 \cdot 2, P=0 \cdot 026)$. Comparing the women with normal TSH but FT4 at the upper and lower ends of the spectrum, women with hypothyroxinaemia ( $n 52)$ had significantly lower plasma $\mathrm{Zn}$ concentrations than those with hyperthyroxinaemia $(n 32, T(80)=2 \cdot 3, P=0 \cdot 023)$. With regard to plasma $\mathrm{Cu}$, women with clinical hypothyroidism had the lowest mean concentrations and those with clinical hyperthyroidism the highest, and these were significantly different: $T(26)=2 \cdot 6$, $P=0 \cdot 016$. Also, women with clinical hyperthyroidism had significantly higher plasma $\mathrm{Cu}$ concentrations than the euthyroid group: $T(1850)=2 \cdot 1, P=0 \cdot 027$. There were no differences in the occurrence of thyroid dysfunction sub-groups between the groups with and without $\mathrm{Se} / \mathrm{Zn} / \mathrm{Cu}$ supplement intake.

Table 4A shows several linear regression analyses with logFT4 and $\operatorname{logTSH}$ as dependent variables and plasma $\mathrm{Se} / \mathrm{Zn} / \mathrm{Cu}$ 
Table 3. Different sub-groups of first-trimester thyroid (dys)function in 2041 pregnant women and their concentrations of plasma mineral selenium, zinc and copper

(Numbers and percentages; mean values and standard deviations)

\begin{tabular}{|c|c|c|c|c|c|c|c|c|c|c|}
\hline & \multirow[b]{2}{*}{$n$} & \multirow[b]{2}{*}{$\%$} & \multicolumn{2}{|c|}{$\begin{array}{l}\text { TPO-Ab+ } \\
(>35 \mathrm{IU} / \mathrm{l})\end{array}$} & \multicolumn{2}{|c|}{$\mathrm{Se}$} & \multicolumn{2}{|c|}{$\mathrm{Zn}$} & \multicolumn{2}{|c|}{$\mathrm{Cu}$} \\
\hline & & & $n$ & $\%$ & Mean & SD & Mean & SD & Mean & SD \\
\hline Euthyroid women & 1835 & 89.9 & 133 & $7 \cdot 2$ & 1.00 & 0.14 & $12 \cdot 6$ & 1.8 & $26 \cdot 3$ & 4.7 \\
\hline Overt hypothyroidism & 11 & 0.5 & 10 & 90.9 & 1.02 & 0.14 & $13 \cdot 1$ & 2.6 & 23.7 & 5.4 \\
\hline Overt hyperthyroidism & 17 & 0.8 & 0 & 0 & 0.98 & 0.16 & 13.6 & 2.0 & $28 \cdot 8$ & 4.9 \\
\hline Sub-clinical hypothyroidism & 67 & 3.3 & 23 & 34.3 & 1.01 & 0.16 & $12 \cdot 7$ & $2 \cdot 1$ & 26.5 & $5 \cdot 2$ \\
\hline Sub-clinical hyperthyroidism & 29 & 1.4 & 3 & $10 \cdot 3$ & 0.99 & 0.16 & $12 \cdot 2$ & 1.7 & $26 \cdot 1$ & $5 \cdot 1$ \\
\hline Hypothyroxinaemia & 52 & 2.5 & 7 & 13.5 & 1.02 & 0.18 & $12 \cdot 0$ & 1.6 & $25 \cdot 9$ & $5 \cdot 3$ \\
\hline Hyperthyroxinaemia & 30 & 1.5 & 3 & 10 & 1.01 & 0.16 & $12 \cdot 9$ & $2 \cdot 3$ & $26 \cdot 8$ & 4.5 \\
\hline
\end{tabular}

TPO-Ab, thyroid peroxidase antibodies; TSH, thyrotropin; FT4, free thyroxine.

* Reference range for TSH: 0.23-4.0 IU/l; for FT4: 11.5-18 pmol//, 2.5th and 97.5th percentile in TPO-Ab (<35 IU/I)-negative women. Euthyroid: normal TSH and FT4. Overt thyroid dysfunction: TSH and FT4 outside reference range. Sub-clinical thyroid dysfunction: normal FT4 with TSH outside reference range. Hypothyroxinaemia: FT4<2.5th percentile, normal TSH; hyperthyroxinaemia: FT4 > 97.5th percentile, normal TSH.

Table 4. Linear regression with log free thyroxine (logFT4) and log thyrotropin (logTSH) as dependent variables, adjusted for intake of selenium, zinc and copper supplements, parity, BMI, smoking, age and family history of thyroid dysfunction

(Standardised $\beta$ values and $P$ values; $n$ 2041)

\begin{tabular}{|c|c|c|c|c|}
\hline & \multicolumn{2}{|c|}{ LogFT4 } & \multicolumn{2}{|c|}{$\log \mathrm{TSH}$} \\
\hline & Standardised $\beta$ & $P$ & Standardised $\beta$ & $P$ \\
\hline \multicolumn{5}{|c|}{ A. Independent separately } \\
\hline $\mathrm{Se}$ & -0.030 & 0.20 & 0.060 & 0.009 \\
\hline $\mathrm{Zn}$ & 0.084 & $<0.001$ & -0.018 & 0.41 \\
\hline $\mathrm{Cu}$ & 0.079 & 0.001 & -0.062 & 0.008 \\
\hline \multicolumn{5}{|c|}{ B. Independent together: Se, $\mathrm{Cu}$ and $\mathrm{Zn}$} \\
\hline $\mathrm{Se}$ & -0.058 & 0.014 & 0.075 & 0.001 \\
\hline $\mathrm{Zn}$ & 0.096 & $<0.001$ & -0.032 & 0.14 \\
\hline $\mathrm{Cu}$ & 0.091 & $<0.001$ & -0.072 & 0.002 \\
\hline
\end{tabular}

concentrations separately as dependent variables, adjusted for parity, BMI, smoking, family history of thyroid dysfunction and age. We also adjusted for intake of $\mathrm{Se} / \mathrm{Zn} / \mathrm{Cu}$ supplements.

Plasma Se was not related to logFT 4 but significantly, independently and positively related to logTSH; higher plasma Se concentration was related to higher TSH. Plasma $\mathrm{Zn}$ and $\mathrm{Cu}$ concentrations were both positively and independently related to $\operatorname{logFT} 4$; higher plasma $\mathrm{Zn}$ and $\mathrm{Cu}$ concentrations were associated with higher FT4. Plasma Cu (but not Zn) concentration was negatively associated with logTSH. Because of a possible interaction between the trace elements, we subsequently entered $\mathrm{Se}, \mathrm{Zn}$ and $\mathrm{Cu}$ together into the regression (Table 4B) adjusting for the same covariates. Plasma Se (negatively), $\mathrm{Zn}$ and $\mathrm{Cu}$ (both positively) concentrations were all related to logFT4; plasma Se and $\mathrm{Cu}$ (but not $\mathrm{Zn}$ ) concentrations were also related to $\log \mathrm{TSH}$. The $\mathrm{Cu} / \mathrm{Zn}$ plasma concentration ratio was not related to $\operatorname{logFT} 4$ nor to $\log \mathrm{TSH}$ (data not shown).

We finally looked at the TPO-Ab status. Mean plasma mineral $\mathrm{Se} / \mathrm{Zn} / \mathrm{Cu}$ concentrations did not differ between TPO-Ab+ and TPO-Ab- women. However, the number of women with elevated TPO-Ab titre at 12 weeks' gestation in those not taking $\mathrm{Se} / \mathrm{Zn} / \mathrm{Cu}$ supplements was 61 (11.2\%) compared with 118 $(7.9 \%)$ in those taking these supplements $\left(\chi^{2} \quad(1)=5.5\right.$, $P=0 \cdot 019)$. Women taking additional $\mathrm{Se} / \mathrm{Zn} / \mathrm{Cu}$ supplements were 1.46 times less likely (95\% CI 1.09, 2.04) to have an elevated titre of TPO-Ab at 12 weeks' gestation.

\section{Discussion}

The present study reports reference ranges $(2 \cdot 5$ th- $97 \cdot 5$ th percentiles), means and median concentrations of plasma mineral ( $\mathrm{Se}, \mathrm{Zn}$ and $\mathrm{Cu}$ ) in an appropriately large sample of healthy pregnant women not taking supplements of these trace elements. It also shows that intake of $\mathrm{Se} / \mathrm{Zn} / \mathrm{Cu}$ supplements significantly affects plasma Se concentration but not plasma $\mathrm{Zn}$ and $\mathrm{Cu}$ concentrations. Moreover, it shows that, at 12 weeks' gestation, different sub-groups of women with thyroid dysfunction showed different concentrations of plasma $\mathrm{Zn}$ and $\mathrm{Cu}$, though not Se concentration, than did euthyroid women. Plasma Zn concentration was significantly lower in women with hypothyroxinaemia than in euthyroid women. Women with overt hyperthyroidism showed the highest plasma $\mathrm{Cu}$ concentrations. After adjustment for covariates (including the intake of $\mathrm{Se} / \mathrm{Zn} / \mathrm{Cu}$ supplements), linear regression showed that plasma $\mathrm{Cu}$ and $\mathrm{Zn}$ concentrations separately and in combination were positively related to FT4. Plasma $\mathrm{Cu}$ concentration was inversely related to TSH, while plasma Se concentration was positively correlated with TSH. TPO-Ab status at 12 weeks' gestation was not related to plasma mineral $\mathrm{Se} / \mathrm{Zn} / \mathrm{Cu}$ concentrations. However, women taking $\mathrm{Se} / \mathrm{Zn} / \mathrm{Cu}$ supplements were less likely to have elevated titres of TPO-Ab at 12 weeks' gestation.

The reference range of plasma Se concentration in the present study of the total sample $(0 \cdot 75-1.31 \mu \mathrm{mol} / \mathrm{l})$ is similar to that in a previous study in the same area in a sample of 1000 women, although assessed in serum: $0 \cdot 77-1.32 \mu \mathrm{mol} /$ $\mathrm{l}^{(22)}$. However, in the sub-group without trace element intake in the present study, the reference range was lower (0.72$1.25 \mu \mathrm{mol} / \mathrm{l})$ than in the previous study, which was performed in 2003-2004. At that time, supplement intake was not carefully assessed, so there are no comparable data available. The median of $0.94 \mu \mathrm{mol} / 1$ plasma Se in the sub-group of the present study not taking these trace elements is low, but the Netherlands (as is Europe in general) is known as a (mildly) Se-deficient area ${ }^{(23)}$. Another possibility is that during the first trimester, there is an 
increased turnover of Se due to immune tolerance processes or increased thyroid hormone production. In the group of women with Se supplement intake, the median was much higher (1.02 $\mu \mathrm{mol} / \mathrm{l})$ suggesting that a daily dose of $27.5-55 \mu \mathrm{g}$ Se is able to increase plasma Se concentrations (there were no differences in baseline characteristics between the two groups). In the USA National Health and Nutrition Examination Survey (NHANES) 2011-2014, the plasma Se reference range in women was $1 \cdot 83-3 \cdot 10 \mu \mathrm{mol} / 1$ (144.2-244.6 $\mu \mathrm{g} / \mathrm{l})$ but without correction for possible supplement intake ${ }^{(16)}$. It is obvious that in the present study, the reference ranges are sex-and age-specific, that is, they relate to women of fertile age. In the NHANES study, the Se reference range increased with age and was higher in males ${ }^{(16)}$. A recent study from Australia reported a mean serum Se concentration of $0.73 \mu \mathrm{mol} / 1$ at 15 weeks' gestation in 894 primiparous women without fertility problems ${ }^{(24)}$. As in the present study, over $90 \%$ were white Caucasian women but the mean age (23.4 (SD 5.0) years) was substantially lower. There were no data on women not taking Se-containing supplements. The study of Alvarez et al. in Spanish pregnant women showed a much higher mean serum Se at first trimester, that is, $1.38 \mu \mathrm{mol} / 1$, which decreased significantly to $1.08 \mu \mathrm{mol} / 1$ at term ${ }^{(25)}$. However, no intake of supplements was mentioned in that study either.

The reference range for plasma $\mathrm{Zn}$ concentration (9.6-16.4 $\mu \mathrm{mol} / \mathrm{l}$ ) in women not taking $\mathrm{Zn}$ supplements is comparable to that in another study in adult non-pregnant females, that is, $10-18 \mu \mathrm{mol} / \mathrm{l}^{(26)}$. In the USA (NHANES 2011-2014 data), the $2 \cdot 5$ th-97.5th percentiles of serum $\mathrm{Zn}$ concentration in 659 non-pregnant women between 19 and 30 years of age were $8.5-16.5 \mu \mathrm{mol} / 1(55.7-107.9 \mu \mathrm{g} / \mathrm{dl})$ which is also close to that of the present study ${ }^{(26)}$. Again, intake of Zn-containing supplements in the present study did not result in higher mean or median plasma $\mathrm{Zn}$ concentration than in women not taking $\mathrm{Zn}$. This seems to be in line with the US study where serum $\mathrm{Zn}$ concentrations were not related to dietary or supplemental $\mathrm{Zn}$ intake ${ }^{(26)}$. The mean serum $\mathrm{Zn}$ concentration in the Australian study was 9.4 (SD 2.2) $\mu \mathrm{mol} / 1$, which is comparable with the value found in our study ${ }^{(24)}$.

Interestingly, the reference range for plasma $\mathrm{Cu}$ concentrations of the total group in the present study, $17 \cdot 6-36 \cdot 4 \mu \mathrm{mol} / \mathrm{l}$, was almost the same as that of the sub-group that was not taking $\mathrm{Cu}$ supplements that is, $17 \cdot 2-36 \cdot 0 \mu \mathrm{mol} / \mathrm{l}$. The standard dose of $\mathrm{Cu}$ in almost all pregnancy supplements in the Netherlands is $1 \mathrm{mg} / \mathrm{d}$. There are several explanations for not finding a change with supplement taking: the Netherlands is $\mathrm{Cu}$ sufficient, which explains why further $\mathrm{Cu}$ intake will not increase plasma $\mathrm{Cu}$ concentrations. But a recent review showed that serum $\mathrm{Cu}$ seems to respond to supplementation only at a higher $\operatorname{dose}^{(7)}$. During the first 3 months of pregnancy, the modest dose of the $\mathrm{Cu}$ supplements of $1 \mathrm{mg} / \mathrm{d}$ does not seem to meet the substantial physiological drop in serum $\mathrm{Cu}$ concentration. It should be noted that the plasma $\mathrm{Cu}$ concentration reference range in the present study is much higher than in the reference population of adult females $(10-24 \mu \mathrm{mol} / \mathrm{l})^{(7)}$. In the Australian study mentioned above, the mean serum $\mathrm{Cu}$ concentration was 30.3 (SD 5.4) $\mu \mathrm{mol} / 1$ which is higher than that in the present study $(26.5 \mu \mathrm{mol} / \mathrm{l})^{(24)}$. In the Chinese study, the reference range of serum $\mathrm{Cu}$ concentrations in the first trimester was substantially lower: $9 \cdot 5-25 \cdot 8 \mu \mathrm{mol} / \mathrm{l}^{(9)}$. These comparisons illustrate the differences between countries in reference ranges of several trace elements, which are mostly to be explained by eating habits and probably by ethnic differences.

Several studies demonstrated a decrease in the concentration of serum $\mathrm{Zn}$ concentration and, as found in other studies, an increase in the concentration of plasma and serum $\mathrm{Cu}$ concentrations with progression of pregnancy ${ }^{(27-29)}$. The decrease in serum $\mathrm{Zn}$ concentration can be explained by maternal-fetal transfer and disproportionate increase of plasma volume, while the increase in copper binding proteins, that is, ceruloplasmin, the secretion of which is stimulated by maternal oestrogen as well as decreased biliary $\mathrm{Cu}$ excretion, might explain the increase in $\mathrm{Cu}$ concentration throughout the pregnancy ${ }^{(9)}$.

Plasma Se concentration was positively (and independently) associated with TSH - the higher the Se, the higher the TSH while it was not correlated with FT4. This is difficult to explain because Se is important for the synthesis of thyroid hormone ${ }^{(5)}$. The most likely explanation is that human chorionic gonadotropin (hCG) at 10-12 weeks' gestation is highly elevated for several reasons, including the transformation of the post-ovulatory ovary into the gravid corpus luteum for the production of progesterone and oestradiol as well as for the augmentation of immune tolerance by promoting regulatory $\mathrm{T}$-cell recruitment ${ }^{(30)}$. The glycoprotein, hCG, has an $\alpha$-subunit displaying homology with TSH; therefore, during early gestation, the 'classical' negative feedback loop between TSH and FT4 is partly overwhelmed by hCG ${ }^{(1,31)}$. This will result in lower TSH and higher FT4 concentrations 'contaminating' the definition of hyperthyroidism. Thus, high Se would normally result in appropriate amounts of FT4, downsizing TSH, but during early gestation, the TSH action of hCG might interfere with Se-dependent thyroid hormone synthesis.

In the NHANES 2011-2014 study, serum Cu concentration was also positively associated with TT4 and TT3 in non-pregnant females with no association for either serum $\mathrm{Zn}$ or Se (with TSH) concentrations $^{(16)}$. To the best of our knowledge, there are no previous reports suggesting that plasma $\mathrm{Zn}$ concentrations in pregnant women with hypothyroxinaemia and overt thyroid dysfunction (hypo- as well as hyperthyroidism) differ from those in euthyroid women. This finding is intriguing but somewhat contrary to what would be expected. A 'direct' effect was suggested in a recent review that suggested that $\mathrm{Zn}$ had a role in thyroid-hormone metabolism by regulating deiodinase activity and the synthesis of thyroid releasing hormone and $\mathrm{TSH}^{(14)}$; that could explain the association found in the present study between hypothyroxinaemia and relatively low plasma $\mathrm{Zn}$ concentrations. A recent meta-analysis showed that patients with autoimmune disorders (including thyroid disorders) predominantly show lower serum and plasma $\mathrm{Zn}$ concentrations than in healthy controls ${ }^{(32)}$. In Table 3, women with (sub)clinical hypothyroidism had the highest incidence of elevated TPO-Ab titre, suggesting an autoimmune origin of poor thyroid function. In the NHANES 2011-2014 study, the low serum Zn concentration cut-off for females $>10$ years of age was between 9.2 and $10 \cdot 7 \mu \mathrm{mol} / \mathrm{l}(60-70 \mu \mathrm{g} / \mathrm{dl})$, depending on the time of day when the assessment was carried out ${ }^{(26)}$. In the present study, there were twenty-eight women with plasma $\mathrm{Zn}$ concentrations 
below the cut-off of $9.2 \mu \mathrm{mol} / \mathrm{l}$. Those women were 3.6 times (95\% CI $1 \cdot 12,12 \cdot 4, P=0.032$ ) more likely to have subclinical hypothyroidism at 12 weeks' gestation. It could be hypothesised that low $\mathrm{Zn}$ concentrations enhance (autoimmune) destruction of thyroid cells, as is the case in both Hashimoto's thyroiditis and Graves' disease ${ }^{(1,3)}$. However, the highest mean plasma $\mathrm{Zn}$ concentrations were found in women with overt hyperthyroidism (Table 3) though none of these women showed elevated concentrations of TPO-Ab, suggesting another origin of thyroid dysfunction than auto-immunity. However, a possible relationship between plasma $\mathrm{Zn}$ concentrations and hCG (both of which are important immune modulators) remains to be established. This also seems to be the case for $\mathrm{Cu}$ : the highest mean plasma $\mathrm{Cu}$ concentration was also found in these hyperthyroid women without elevated TPO-Ab titres.

The mean concentration of the plasma mineral Se/Zn/Cu was not related to TPO-Ab status. However, women with $\mathrm{Se} / \mathrm{Zn} / \mathrm{Cu}$ supplement intake were 1.4 times less likely to have elevated TPO-Ab titre at 12 weeks' gestation. A recent review highlighted the effect of serum/plasma $\mathrm{Zn}$ concentrations on the maturation of $\mathrm{T}$ cells and the balance between different T-cell subsets ${ }^{(33)}$. Similarly, Se and $\mathrm{Cu}$ are involved in the stimulation of T-reg cell formation, crucial for pregnancy immune tolerance ${ }^{(4,33)}$. It might be hypothesised that the intake of these trace elements will benefit pregnancy immune tolerance to the fetal allograft. It is also known that an epi-phenomenon of immune tolerance is the decrease in antibodies (markers of auto-immune syndromes), including TPO-Ab, which might explain the lower prevalence of an elevated titre in women taking these trace elements ${ }^{(1)}$.

The present study has several strengths and limitations. A major strength is the relatively high number of pregnant women enabling detection of a group of 544 women not taking Se/Zn/ $\mathrm{Cu}$ supplements and that is sufficiently large to define accurately the 2.5 th- 97.5 th reference ranges. Also the total number of women in the sample enabled us to define first-trimester-specific reference ranges of TSH and FT4, and sub-groups of hypo- and hyperthyroxinaemia with appropriate power.

A major limitation of the study is that pre-pregnancy trace element concentrations were not available; however, previous reports showed that first-trimester serum/plasma Se concentrations accurately reflect pre-pregnancy concentrations ${ }^{(34)}$. In the Chinese study, serum $\mathrm{Cu}$ and $\mathrm{Zn}$ concentrations were compared with those of a matched non-pregnant control group ${ }^{(9)}$. Throughout pregnancy, serum Cu concentrations were significantly higher than in non-pregnant controls but the intake of pregnancy supplements was not assessed. Serum Zn concentrations were significantly lower during mid-gestation than in non-pregnant controls ${ }^{(9)}$. With increasing gestation, serum $\mathrm{Cu}$ concentrations increased but there was no correlation between serum $\mathrm{Zn}$ concentrations and gestational age ${ }^{(9)}$. During pregnancy, there is a substantial expansion of blood volume but predominantly after the first trimester. During the first 10-12 weeks, the average weight gain is about $0.5-2 \mathrm{~kg}$, which will not explain a possible drop of trace element concentrations due to substantial blood volume expansion ${ }^{(35)}$. Also, in the present study, nonfasting assessments of $\mathrm{Zn}$ were analysed but, as shown in the NHANES 2011-2014 study, meal consumption results in a decrease in serum $\mathrm{Zn}$ concentrations, which is cumulative following repeated meals, whereas overnight and daytime fasting result in increased circulating $\mathrm{Zn}$ concentrations ${ }^{(26)}$. In the Netherlands, there is a nationwide blood assessment at 12 weeks' gestation. Therefore, standardised tubes are used which do not meet the guidelines of the International Zinc Nutrition Consultative Group to avoid contamination. Another limitation is that ferritin concentrations were not assessed. Low ferritin levels are common during pregnancy, and some research has suggested an opposite effect on $\mathrm{Zn}$ and $\mathrm{Cu}$ concentrations. However, in a Norwegian study of 2982 pregnant women, low plasma ferritin concentration $(<12 \mu \mathrm{g} / \mathrm{l}$, assessed at 18 weeks' gestation) was significantly associated with lower plasma Se concentration but not significantly with (higher) plasma $\mathrm{Zn}$ and $\mathrm{Cu}$ concentrations ${ }^{(10)}$. Also, the cross-sectional design of the present study does not enable us to draw conclusions with regard to the direction of associations that were found. Our sample consisted primarily of white Caucasian women, which prohibits the generalisability of the findings to the $20 \%$ of Dutch pregnant women of non-Caucasian origin. Studies in the USA show significant differences in trace element concentrations by ethnic background ${ }^{(16)}$. Against this background, comparisons of the present study with US and Chinese studies should be interpreted with caution. Another limitation is that iodine intake, the most important determinant of adequate thyroid function, was not assessed. However, the Netherlands, unlike the UK, for example, is known to be an iodine-sufficient country ${ }^{(18,36)}$. Because both iodine and Se are crucial for adequate thyroid function ${ }^{(5)}$, it is reasonable to suggest that in iodine-deficient countries, poor iodine status might affect the status of other trace elements such as Se. The subgroups of women with thyroid dysfunction were rather small which means that several (non) existing associations between these sub-groups and plasma $\mathrm{Se} / \mathrm{Zn} / \mathrm{Cu}$ mineral concentrations should be interpreted with caution. A final limitation that must be mentioned is that all studies of plasma/serum mineral Se/Zn/Cu concentrations are subject to the systemic inflammatory response where serum/plasma Se and $\mathrm{Zn}$ concentrations fall and $\mathrm{Cu}$ concentration rises so that values do not reflect the true trace element status $^{(37)}$; even normal pregnancy is an inflammatory state, as evidenced by high cytokine concentrations ${ }^{(38,39)}$.

In conclusion, the first-trimester reference range (2.5th-97.5th percentiles) for plasma Se is largely dependent on supplement intake which is not the case for $\mathrm{Cu}$ and $\mathrm{Zn}$ reference ranges. Plasma Zn concentrations were particularly related to several categories of thyroid dysfunction. Women taking $\mathrm{Se} / \mathrm{Zn} / \mathrm{Cu}$ supplements were less likely to have an elevated TPO-Ab titre in the first trimester.

\section{Acknowledgements}

We thank the pregnant women who participated into the study and the midwives for their important role of recruitment of the pregnant women.

No funding was received.

V. P. was responsible for the design of the study. J. K. was responsible for the analyses of trace elements. V. P. - and the 
department of statistics of Tilburg University - and J. K. were responsible for data analyses. V. P., J. K., W. M. and M. R. were responsible for the writing of the manuscript.

The authors declare that there are no conflicts of interest.

\section{References}

1. Korevaar TIM, Medici M, Visser TJ, et al. (2017) Thyroid disease in pregnancy: new insights in diagnosis and clinical management. Nat Rev Endocrinol 13, 610-622.

2. Maret W (2018) Metallomics: the science of biometals and biometalloids. Adv Exp Med Biol 1055, 1-20.

3. Saeed F, Nadeem M, Ahmed R, et al. (2016) Studying the impact of nutritional immunology underlying the modulation of immune responses by nutritional compounds - a review. Food Agric Immunol 27, 205-229.

4. Wessels I, Maywald M \& Rink L (2017) Zinc as a gatekeeper of immune function. Nutrients $\mathbf{9}, 25$.

5. Rayman MP (2019) Multiple nutritional factors and thyroid disease, with particular reference to autoimmune thyroid disease. Proc Nutr Soc 78, 34-44.

6. Andreini C, Banci L, Bertini I, et al. (2006) Counting the zinc-proteins encoded in the human genome. J Proteome Res 5, 196-201.

7. Bost M, Houdart S, Oberli M, et al. (2016) Dietary copper and human health: current evidence and unresolved issues. J Trace Elem Med Biol 35, 107-115.

8. Lowe NM (2016) Assessing zinc in humans. Curr Opin Clin Nutr Metab Care 19, 321-327.

9. Zhang Z, Yuan E, Liu J, et al. (2013) Gestational age-specific reference intervals for blood copper, zinc, calcium, magnesium, iron, lead, and cadmium during normal pregnancy. Clin Biochem 46, 777-780.

10. Caspersen IH, Thomsen C, Haug LS, et al. (2019) Patterns and dietary determinants of essential and toxic elements in blood measured in mid-pregnancy: The Norwegian Environmental Biobank. Sci Total Environ 671, 299-308.

11. Mousa A, Naqash A \& Lim S (2019) Macronutrient and micronutroient intake during pregnancy: an overview of recent evidence. Nutrition 11, 1-20.

12. Wu Q, Rayman MP, Lv H, et al. (2015) Low population selenium status is associated with increased prevalence of thyroid disease. J Clin Endocrinol Metab 100, 4037-4047.

13. Winther KH, Rayman MP, Bonnema SJ, et al. (2020) Selenium in thyroid disorders - essential knowledge for clinicians. Nat Rev Endocrinol 16, 165-176.

14. Severo JS, Morais JBS, de Freitas TEC, et al. (2019) The role of zinc in thyroid hormones metabolism. Int J Vitam Nutr Res $\mathbf{8 9}$, 80-88.

15. Adamo AM \& Oteiza PI (2010) Zinc deficiency and neurodevelopment: the case of neurons. Biofactors 36, 117-124.

16. Jain RB (2014) Thyroid function and serum copper, selenium and zinc in general US population. Biol Trac Elem Res 159, $87-98$.

17. Truijens SEM, Meems M, Kuppens SM, et al. (2014) The HAPPY study (Holistic Approach to Pregnancy and the first Postpartum Year): design of a large prospective cohort study. $B M C$ Pregnancy Childbirth 14, 312.

18. Pop VJ, Broeren M \& Wiersinga WM (2014) The attitude toward hypothyroidism during early gestation: time for a change of mind. Thyroid 10, 1541-1546.

19. Von Elm E, Altman DG, Egger M, et al. (2007) Strengthening the Reporting of Observational Studies in Epidemiology (STROBE) statement: guidelines for reporting observational studies. BMJ 335, 806-808.

20. Alexander EK, Pearce EN, Brent GA, et al. (2017) 2017 Guidelines of the American Thyroid Association for the diagnosis and management of thyroid disease during pregnancy and the postpartum. Thyroid 27, 315-389.

21. CISI (2008) Defining, Establishing, and Verifying Reference Intervals in the Clinical Laboratory; Approved Guideline, 3rd ed. Wayne, PA: Clinical and Laboratory Standards Institute.

22. Rayman MP, Wijnen H, Vader H, et al. (2011) Maternal selenium status during early gestation and risk for preterm birth. CMAJ 183, 549-555.

23. Stoffaneller R \& Morse NL (2015) A review of dietary selenium intake and selenium status in Europe and the Middle East. Nutrients 17, 1494-1537.

24. Grieger JA, Grzeskowiak LE, Wilson RL, et al. (2019) Maternal selenium, copper and zinc concentrations in early pregnancy, and the association with fertility. Nutrition 11, 1609.

25. Alvarez SJ, Castanon SG, Ruata MLC, et al. (2007) Updating of normal levels of copper, zinc and selenium in serum of pregnant women. J Trace Elem Med Biol 21, 49-52.

26. Hennigar S, Lieberman H, Fuolgoni V, et al. (2018) Serum zinc concentrations in the US population are related to sex, age, and time of blood draw but not dietary or supplemental $\mathrm{Zn}$. J Nutr 148, 1341-1351.

27. Liu J, Yang H, Shi H, et al. (2010) Blood copper, zinc, calcium, and magnesium levels during different duration of pregnancy in Chinese. Biol Trace Elem Res 135, 31-37.

28. Tabrizi FM \& Pakdel FG (2014) Serum level of some minerals during three trimesters of pregnancy in Iranian women and their newborns: a longitudinal study. Indian J Clin Biochem 29, 174-180.

29. Khoushabi F, Shadan MR, Miri A, et al. (2016) Determination of maternal serum zinc, iron, calcium and magnesium during pregnancy in pregnant women and umbilical cord blood and their association with outcome of pregnancy. Mater Sociomed 28, 104-107.

30. Schumacher A (2017) Human chorionic gonadotropin as a pivotal endocrine immune modulator initiating and preserving fetal tolerance. Int J Mol Sci 18, 2166-2175.

31. Nwabuobi C, Arlier S, Schatz F, et al. (2017) hCG: biological functions and clinical applications. Int J Mol Sci 18, 2037-2052.

32. Sanna A, Firinu D, Zavattari P, et al. (2018) Zinc status and autoimmunity: a systematic review and meta-analysis. Nurtients 10, E68.

33. Elmadfa I \& Meyer AL (2019) The role of the status of selected micronutrients in shaping the immune function. Endocr Metab Immune Disord Drug Targets 19, 1100-1115.

34. Rayman MP, Bath SC, Westaway J, et al. (2015) Selenium status in U.K. pregnant women and its relationship with hypertensive conditions of pregnancy. Br J Nutr 113, 249-258.

35. Kominiarek MA \& Peaceman AM (2017) Gestational weight gain. Am J Obstet Gynecol 217, 642-651.

36. Bath SC (2017) Iodine supplementation in pregnancy in mildly deficient regions. Lancet Diabetes Endocrinol 5, 840-841.

37. Oakes EJ, Lyon TD, Duncan A, et al. (2008) Acute inflammatory response does not affect erythrocyte concentrations of copper, zinc and selenium. Clin Nutr 27, 115-120.

38. Kristensen K, Wide-Swensson D, Lindstrom V, et al. (2009) Serum amyloid a protein and C-reactive protein in normal pregnancy and preeclampsia. Gynecol Obstet Invest 67, 275-280.

39. Buxton MA, Meraz-Cruz N, Sánchez BN, et al (2020) Repeated measures of cervicovaginal cytokines during healthy pregnancy: understanding "normal" inflammation to inform future screening. Am J Perinatol 37, 613-620. 